\title{
Can we use non-invasive parameters to predict the development of gastroesophageal varices in cirrhotic patients with and without portal vein thrombosis? An observational study from the western region of Saudi Arabia
}

Yasir M Khayyat

\begin{abstract}
Background: The prevention of portal hypertensive complications, including upper gastrointestinal bleeding, is critically important and achieved only through the use of upper endoscopy for the management of oesophageal gastric varices (EGVs). There is a paucity of data and limited utilization of non-invasive predictive parameters to guide the selection of patients who may benefit from endoscopic surveillance, especially in cirrhotic patients with coexistent portal vein thrombosis.

Results: The study was conducted in eight hospitals in the western region of Saudi Arabia over the period of 2015-2017. Among 1349 chronic liver disease patients, eighty-five patients with complete endoscopic findings were included in the study. Twenty-eight patients were diagnosed with non-malignant PVT. Twenty-five patients (89\%) developed oesophageal varices, compared with 57 patients with cirrhosis without PVT. A predictive factor for the development of oesophageal varices of statistical significance was hypoalbuminemia in PVT patients $(p=0.04)$. No statistically significant differences were found in other biochemical markers $(p<0.05)$ between the PVT and non-PVT groups.

Conclusions: The prevalence of oesophageal varices is increased in PVT patients. Serum albumin can be utilized as a predictor of varices development in cirrhosis patients.
\end{abstract}

Keywords: Hypertension, Portal, Portal vein, Oesophageal and gastric varices

\section{Background}

Gastrointestinal (GI) bleeding remains a dreaded concern among acute medical emergencies. Portal hypertensionrelated bleeding has a high risk of morbidity and mortality. In cirrhosis, there is a state of venous stasis in association with coagulation abnormalities secondary to impaired

Correspondence: ymkhayyat@uqu.edu.sa

Department of Medicine, Faculty of Medicine, Umm AlQura University, Makkah, Kingdom of Saudi Arabia

\section{Springer Open}

synthetic liver functions [1]. As a result of this Virchow triad, portal vein thrombosis (PVT) may develop and is a hallmark of a worsened state of decompensation in cirrhosis [2]. This condition is observed in $10-20 \%$ of cirrhotic patients [3] and detected within the first year in $7.4-16 \%$ of patients [4]. Failure to control gastrointestinal bleeding on initial presentation is associated with the presence of PVT [5] and vice versa, where the presence of previous upper GI bleeding is associated with PVT $[6,7]$.

(c) The Author(s). 2021 Open Access This article is licensed under a Creative Commons Attribution 4.0 International License, which permits use, sharing, adaptation, distribution and reproduction in any medium or format, as long as you give appropriate credit to the original author(s) and the source, provide a link to the Creative Commons licence, and indicate if changes were made. The images or other third party material in this article are included in the article's Creative Commons licence, unless indicated otherwise in a credit line to the material. If material is not included in the article's Creative Commons licence and your intended use is not permitted by statutory regulation or exceeds the permitted use, you will need to obtain permission directly from the copyright holder. To view a copy of this licence, visit http://creativecommons.org/licenses/by/4.0/. 
Gastroesophageal varices were observed in $50 \%$ of cirrhotic patients, with mortality following the first episode of upper GI bleeding increasing exponentially with time at 6 weeks, reaching $15-20 \%$ to $40 \%$ risk within 1 year. Predictors of the first bleeding episode in cirrhosis, in addition to the advanced stage of liver disease and advanced high-risk features of bleeding on varices [8], are coexistent bacterial infections, especially spontaneous bacterial peritonitis [9]. Large varices harbour an increased risk of bleeding and are associated with a high ChildPugh-Turcott (CPT) class [10]. The risk has to be prevented by early detection of high-risk gastroesophageal varices that are precisely and accurately staged and managed through the performance of upper endoscopy. The aim of our study was to evaluate possible non-invasive patient-related factors that would be helpful in predicting the finding of portal hypertensive gastroesophageal varices on upper endoscopy in cirrhotic patients with PVT compared with cirrhotic patients without PVT (control group) who may benefit from early surveillance for detection and primary prophylaxis in a cohort of patients in the western region of Saudi Arabia.

\section{Methods}

\section{Patient characteristics}

This observational study evaluated patients with a diagnosis of chronic liver disease. The inclusion criterion was adult patients (above the age of 14 years) with liver cirrhosis that was confirmed by clinical, laboratory, and radiological investigations. The exclusion criteria were as follows: age under 14 years, the presence of intraabdominal infections and inflammatory conditions, and the presence of abdominal or systemic malignancy, including patients on systemic chemotherapy, those with hereditary thrombophilia, and those with hepatocellular carcinoma.

\section{Patient selection}

The study was conducted at tertiary hospitals in two cities in the western region of Saudi Arabia from 2015 to 2017. Hospital records were reviewed for patients with a diagnosis of PVT and its corresponding International Classification of Diseases (ICD-10) code I-81 for patients with a diagnosis of PVT (cirrhosis with PVT group) on greyscale and Doppler ultrasound as well as other imaging modalities which are computerized scan of the abdomen ( $\mathrm{CT}$ abdomen) and magnetic resonance imaging of the abdomen (MRI abdomen) confirmed with a manual search of radiological reports with a diagnosis of PVT that was performed.

Another group of patients with the same inclusion and exclusion criteria with liver cirrhosis but no evidence of PVT (cirrhosis without PVT group) was studied and compared. Diagnostic and therapeutic upper endoscopic reports were reviewed. Findings of portal hypertensive gastroesophageal varices were recorded using the North Italian Endoscopic Club (NIEC)-proposed classification system [10]. Other findings, including duodenal varices and non-portal hypertension-related endoscopic findings, including non-portal hypertensive gastritis, gastric ulcer, non-portal-hypertensive duodenitis, and duodenal ulcer, were included. Blood investigations were complete blood count $(\mathrm{CBC})$ and serum liver function tests (LFTs).

\section{Statistical methods}

Categorical data are presented as frequencies with percentages, while continuous data are summarized as medians with ranges. The relationship between categorical data was tested by the chi-squared statistical test. Continuous data were subjected to the Shapiro-Wilk test to evaluate normality. The Mann-Whitney $U$ test was used to compare continuous data. Univariate and multivariate regression analyses were conducted to evaluate the association between categorical outcome and a set of covariates. Independent variables that were significant in the univariate regression analysis were retained for the multivariate regression. A $p$ value of less than 0.05 was considered statistically significant. Statistical analysis was carried out using StataCorp 2013 [11].

The study was reviewed and approved by the institutional review boards of the participating hospitals in two cities in the western region of Saudi Arabia.

\section{Results}

A total of 1349 patients with chronic liver disease records were retrieved and reviewed in the western region of Saudi Arabia during the study period. ICD-10 codes of clinical diagnosis were used (portal vein thrombosis, I-81; mesenteric embolism and thrombosis, K-55; oesophageal varices, I-85; gastric varices, I-86.4). Of the 85 patients with cirrhosis who met the study's inclusion criteria, endoscopic findings were available in twenty-eight cirrhotic patients with portal vein thrombosis and 57 patients with non-portal vein thrombosis. The PVT group included 28 patients (19 males and 9 females), with an overall prevalence of $32.9 \%$. Patients with PVT were younger, with a median age of 54.5 years (versus a median of 63 years in the patients without PVT). Table 1 shows the demographic data, blood parameters, and endoscopic findings for the cirrhosis patients with and without PVT. Sex was not significantly different between the two groups $(p=0.56)$ (Table 1$)$. Regarding haematological parameters, platelet and total protein levels were not significantly different between the two groups of patients. However, albumin was significantly lower in patients with PVT $(p=0.03)$ (Table 1$).$ 
Table 1 Characteristics of cirrhotic patients with and without PVT

\begin{tabular}{|c|c|c|c|c|}
\hline Variables & PVT & Non-PVT & Total & $p$ value \\
\hline Age $^{a}$ (years) & $54.5(17-90)$ & $63(24-91)$ & $61(17-91)$ & 0.01 \\
\hline \multicolumn{5}{|l|}{$\operatorname{Sex}^{b}$} \\
\hline Male & 19 (67.9) & $35(61.4)$ & $54(63.5)$ & \multirow[t]{2}{*}{0.56} \\
\hline Female & $9(32.1)$ & $22(38.6)$ & $31(36.5)$ & \\
\hline \multicolumn{5}{|l|}{ Blood work } \\
\hline Platelets $^{\mathrm{a}}\left(\times 10^{9}\right)$ & $144(23-574)$ & $86(7-371)$ & $98(7-574)$ & 0.06 \\
\hline Total protein ${ }^{a}(\mathrm{~g} / \mathrm{dl})$ & $6.57(4.6-9.4)$ & $6.4(2.6-8.3)$ & $6.5(2.6-9.4)$ & 0.16 \\
\hline Albumin $^{\mathrm{a}}(\mathrm{g} / \mathrm{dl})$ & $2.86(1.2-5)$ & $3.1(0.9-4.4)$ & $2.9(0.9-5)$ & 0.03 \\
\hline \multicolumn{5}{|c|}{ Portal hypertension-related endoscopic findings } \\
\hline Oesophageal varices ${ }^{\mathbf{b}}$ & $25(89.3)$ & $37(66.1)$ & $62(73.8)$ & 0.02 \\
\hline Portal hypertensive gastropathy ${ }^{\mathbf{b}}$ & $18(64.3)$ & $34(60.7)$ & $52(61.9)$ & 0.75 \\
\hline Duodenal varices $^{\mathbf{b}}$ & $1(3.6)$ & $0(0)$ & & 0.16 \\
\hline \multicolumn{5}{|c|}{ Non-portal hypertension-related endoscopic findings } \\
\hline Gastritis $^{\mathbf{b}}$ & $1(3.6)$ & $15(26.8)$ & $16(19.1)$ & 0.01 \\
\hline Gastric ulcer ${ }^{\mathbf{b}}$ & $2(7.1)$ & $2(3.6)$ & $4(4.8)$ & 0.47 \\
\hline Duodenitis $^{\mathbf{b}}$ & $2(7.1)$ & $1(1.8)$ & $3(3.6)$ & 0.21 \\
\hline Duodenal ulcer ${ }^{\mathbf{b}}$ & $5(17.9)$ & $4(7.1)$ & $9(10.7)$ & 0.13 \\
\hline
\end{tabular}

$p<0.05$ is statistically significant

$\mathrm{PH}$ portal hypertension

${ }^{a}$ Quantitative values in brackets are expressed as the median (range)

${ }^{b}$ Categorical variables are expressed as frequencies (percentages)

Oesophageal varices occurred in $89.3 \%$ of patients with PVT. This proportion was significantly higher than that in non-PVT patients, in whom approximately $66 \%$ experienced oesophageal varices $(p=0.02)$ (Table 1$)$.

Among patients with PVT, portal hypertensive gastropathy was highly prevalent, with an incidence of $64.3 \%$; however, this finding was not significantly different $(p=$ 0.75 ). In addition, duodenal varices were not reported among non-PVT patients; however, there was no statistically significant difference between the two groups $(p=$ 0.16) (Table 1).

Regarding non-portal hypertension endoscopic findings, compared to cirrhotic patients without PVT, those with PVT suffered less from gastritis (3.6\% vs. $29.8 \% ; p<0.05)$. On the other hand, however, there was no difference in the prevalence of gastric or duodenal ulcers between the groups $(p>0.05)$. (Table 1$)$.
A detailed comparison of the endoscopic portal hypertensive varices in both cirrhotic groups revealed slightly higher grade 3 oesophageal varices in the PVT group (Table 2).

To propose a predictive factor for the development of oesophageal varices in relation to PVT in cirrhotic patients, a univariate analysis was performed to examine several factors. The odds of oesophageal varices were higher in patients with PVT than in patients without PVT (OR 4.28, 95\% CI 1.14-16; $p=0.031$ ). After controlling for confounders (albumin), the presence of PVT was not associated with oesophageal varices (adjusted OR 3.60, 95\% CI 0.89-14.52; $p=0.072$ ). Low serum albumin levels were significantly associated with the development of oesophageal varices after adjusting for the presence of PVT (OR 0.37, 95\% CI 0.18-0.773; $p=0.04)$ (Table 3).

Table 2 Comparison of variceal findings between the two groups

\begin{tabular}{llll}
\hline Cirrhotic patients & With PVT & Without PVT & P value \\
\hline Non-bleeding grade 1 oesophageal varices & $6(30 \%)$ & $14(70 \%)$ & 0.717 \\
Non-bleeding grade 2 oesophageal varices & $7(28 \%)$ & $18(72 \%)$ & 0.50 \\
Non-bleeding grade 3 oesophageal varices & $9(81.8 \%)$ & $2(33.3 \%)$ & 0.000 \\
Bleeding oesophageal varices & $4(66.6 \%)$ & $2(33.3 \%)$ & 0.72 \\
Non-bleeding gastric varices & $2(66.6 \%)$ & $1(33.3 \%)$ & 0.212 \\
Bleeding gastric varices & $2(100 \%)$ & 0 & 0.43 \\
\hline
\end{tabular}

$p<0.05$ is statistically significant 
Table 3 Univariate and multivariate analyses of factors predicting oesophageal varices

\begin{tabular}{|c|c|c|c|c|}
\hline Risk factor & Odds ratio $(95 \% \mathrm{Cl})$ & $p$ value & Adjusted odds ratio $(95 \% \mathrm{Cl})$ & $p$ value \\
\hline PVT & $4.279(1.144-16.005)$ & 0.031 & $3.598(0.892-14.516)$ & 0.072 \\
\hline Age & $1.014(0.978-1.050)$ & 0.453 & - & - \\
\hline \multicolumn{5}{|l|}{ Sex } \\
\hline Male & Reference & & - & - \\
\hline Female & $0.368(0.136-0.999)$ & 0.050 & - & - \\
\hline Platelet $\left(\times 10^{9}\right)$ & $0.996(0.991-1.002)$ & 0.199 & - & - \\
\hline Albumin (g/dl) & $0.351(0.172-0.715)$ & 0.004 & $0.374(0.181-0.773)$ & 0.04 \\
\hline Total protein (g/dl) & $1.065(0.694-1.636)$ & 0.772 & & \\
\hline
\end{tabular}

$p<0.05$ is statistically significant

\section{Discussion}

Splanchnic venous thrombosis is a rare thrombotic event with a prevalence in the general population of $1 \%$ [12]. Of concern, patients with portomesentric thrombosis, splenic thrombosis, and gastroesophageal varices secondary to cirrhosis-related and non-cirrhosis-related splanchnic thrombosis carry major risks of bleeding [13, 14]. Advanced liver disease is associated with a tendency to suffer from gastrointestinal bleeding, especially portal hypertension-related bleeding, due to hepatic synthetic derangement. There is evidence to suggest an increased risk of mesenteric thrombosis, particularly in those with clinical features of advanced liver disease, such as ascites, systemic and local infection, advanced CPT class, and the presence of thrombotic events at the time of ICU admission, regardless of the aetiology of cirrhosis [15]. Considering the morbidity encountered in end-stage liver disease, which includes variceal bleeding, multiorgan failure, spontaneous bacterial peritonitis, and gastrointestinal bleeding $[2,16]$, efforts to establish a predictive model to diagnose splanchnic thrombosis and recognize portal hypertensive varices are needed. With upper endoscopy being the modality used to diagnose, stage, and manage gastroesophageal varices, there are non-invasive models to predict clinically significant portal hypertension (CSPH), and oesophageal varices include markers of liver synthetic functions, such as INR, albumin, and serum alanine aminotransferase (ALT), which are easily utilized and ordered for follow-up by gastroenterologists and primary care physicians [17]. We studied several available parameters that may be used in general practice and concluded that a finding of low serum albumin is a valid applicable measure in the cirrhotic population with portal vein thrombosis, especially in females. Another easy-to-obtain parameter reported in the literature combines blood and radiological tests; thrombocytopenia, with a platelet count below 88 $[18,19]$, and the ratio of the platelet count to the spleen length score (a ratio $>909\left(\mathrm{n} / \mathrm{mm}^{3}\right) / \mathrm{mm}$ ) have also been used to predict the presence of established oesophageal varices [20]. Considering the common incidence and prevalence of chronic liver disease and cirrhosis in our region, the presence of portal vein thrombosis in the study cohort was small, making our study limited by a small sample size that may affect the reproducibility of the findings. It could be argued that the presence of liver cirrhosis with its associated advanced portal hypertension would include impaired synthetic function (i.e. hypoalbuminemia and a bleeding tendency bleeding secondary to impaired synthetic factors), and the report of our findings might not add much to the previously known incidence of portal vein thrombosis; however, our findings would add to the previously known facts and support the consideration of the use of serum albumin along with platelet count as an initial assessment in patients with cirrhosis and associated PVT. Our geographical area has a higher prevalence of viral-induced liver disease than other areas of the world, and viral-induced liver disease may differ from cirrhosis due to alcoholic liver disease in terms of disease behaviours, thereby limiting the generalizability of our findings. Future research needs to address the different stages of mesenteric and portal vein thrombosis and its haemodynamic influence on portal pressure to understand the appropriate stages of intervention, which could add further preventative steps to decrease morbidity and mortality in chronic liver disease.

\section{Conclusions}

Our study demonstrated that in patients with cirrhosis, there is an increased prevalence of oesophageal varices in patients with PVT mostly with a higher grade of varices. Utilizing easily available blood parameters, it was shown that serum albumin can be used as a noninvasive indicator of the development of oesophageal varices. Future interventional studies to provide predictive and diagnostic values of serum albumin as a biomarker of oesophageal varices are warranted.

\section{Abbreviations}

PVT: Portal vein thrombosis; EGVs: Oesophageal gastric varices; Gl: Gastrointestinal; CPT: Child-Pugh-Turcott; ICD-10: International

Classification of Diseases version 10; CBC: Complete blood count; LFT: Liver function test; NIEC: North Italian Endoscopy Club; CSPH: Clinically significant portal hypertension; ALT: Alanine aminotransferase 


\section{Acknowledgements}

The authors would like to thank Dr. Ahmad Mirza for his support and advice with the statistical tests and the Ministry of Health (Makkah and Jeddah Regions) and research centres affiliated with the hospitals of the western region of Saudi Arabia.

\section{Author's contributions}

YK contributed to the data collection, drafting of the manuscript, and review of the final draft. The author read and approved the final manuscript.

\section{Funding}

None

\section{Availability of data and materials}

The data that support the findings of this study are available on request from the corresponding author.

\section{Declarations}

\section{Ethics approval and consent to participate}

Consent was waived due to the retrospective nature of the study.

City of Makkah: Al Noor Specialist Hospital, Heraa General Hospital: Letter of approval M47/301/83776

City of Jeddah: King Fahd General Hospital, King Abdul Aziz Hospital, Althagr General Hospital: Faculty of Medicine, Umm Al Qura University Letter VDMed-660

Fakeeh Hospital Jeddah: Approval No: 06/REC/2009

King Faisal Specialist Hospital and Research Centre Jeddah, Approval No: IRB 2009-26

\section{Consent for publication}

None applicable.

\section{Competing interests}

The author declares that he has no competing interests.

Received: 16 December 2020 Accepted: 30 March 2021

Published online: 07 April 2021

\section{References}

1. Amitrano L, Guardascione MA, Ames PR (2007) Coagulation abnormalities in cirrhotic patients with portal vein thrombosis. Clin Lab 53(9-12):583-589

2. Nery F, Chevret $S$, Condat B, de Raucourt E, Boudaoud L, Rautou PE, Plessier A, Roulot D, Chaffaut C, Bourcier V, Trinchet JC, Valla DC (2015) Causes and consequences of portal vein thrombosis in 1,243 patients with cirrhosis: results of a longitudinal study. Hepatology 61:660-667. https://doi.org/10.1 002/hep.27546

3. Fimognari FL, Violi F (2008) Portal vein thrombosis in liver cirrhosis. Intern Emerg Med 3:213-218. https://doi.org/10.1007/s11739-008-0128-0

4. Amitrano L, Guardascione MA (2009) Management of portal vein thrombosis in cirrhotic patients. Mediterr J Hematol Infect Dis 1:e2009014

5. D'Amico G, De Franchis R (2003) Upper digestive bleeding in cirrhosis. Posttherapeutic outcome and prognostic indicators. Hepatology 38(3):599-612 https://doi.org/10.1053/jhep.2003.50385

6. Violi F, Corazza GR, Caldwell SH, Perticone F, Gatta A, Angelico M, Farcomeni A, Masotti M, Napoleone L, Vestri A, Raparelli V, Basili S (2016) Portal vein thrombosis relevance on liver cirrhosis: Italian Venous Thrombotic Events Registry. Intern Emerg Med 11:1059-1066. https://doi. org/10.1007/s11739-016-1416-8

7. Qi X, Su C, Ren W, Yang M, Jia J, Dai J, Xu W, Guo X (2015) Association between portal vein thrombosis and risk of bleeding in liver cirrhosis: a systematic review of the literature. Clin Res Hepatol Gastroenterol 39:683691. https://doi.org/10.1016/j.clinre.2015.02.012

8. North Italian Endoscopic Club for the Study and Treatment of Esophageal Varices (1988) Prediction of the first variceal hemorrhage in patients with cirrhosis of the liver and esophageal varices. A prospective multicenter study. N Engl J Med 319:983-989. https://doi.org/10.1056/NEJM1988101331 91505

9. Zhao C, Chen SB, Zhou JP, Xiao W, Fan HG, Wu XW, Feng GX, He WX (2002) Prognosis of hepatic cirrhosis patients with esophageal or gastric variceal hemorrhage: multivariate analysis. Hepatobiliary Pancreat Dis Int 1:416-419
10. Calès $P$, Desmorat $H$, Vinel JP, Caucanas JP, Ravaud A, Gerin P, Brouet $P$, Pascal JP (1990) Incidence of large oesophageal varices in patients with cirrhosis: application to prophylaxis of first bleeding. Gut 31:1298-1302. https://doi.org/10.1136/gut.31.11.1298

11. StataCorp (2013) Stata Statistical Software: release 13. StataCorp LP, College Station

12. Ageno W (2015) Managing unusual presentations of venous thromboembolism. J Thromb Thrombolysis 39:304-310. https://doi.org/10.1 007/s11239-015-1171-0

13. Amitrano L, Guardascione MA, Scaglione M, Pezzullo L, Sangiuliano N, Armellino MF, Manguso F, Margaglione M, Ames PR, lannaccone L, Grandone E, Romano L, Balzano A (2007) Prognostic factors in noncirrhotic patients with splanchnic vein thromboses. Am J Gastroenterol 102:24642470. https://doi.org/10.1111/j.1572-0241.2007.01477.x

14. Thatipelli MR, McBane RD, Hodge DO, Wysokinski WE (2010) Survival and recurrence in patients with splanchnic vein thromboses. Clin Gastroenterol Hepatol 8:200-205. https://doi.org/10.1016/j.cgh.2009.09.019

15. Muciño-Bermejo J, Carrillo-Esper R, Méndez-Sánchez N, Uribe M (2015) Thrombosis and hemorrhage in the critically ill cirrhotic patients: five years retrospective prevalence study. Ann Hepatol 14:93-98. https://doi.org/10.1 016/S1665-2681(19)30805-1

16. Garcia-Pagán JC, Hernández-Guerra M, Bosch J (2008) Extrahepatic portal vein thrombosis. Semin Liver Dis 28:282-292. https://doi.org/10.1055/s-002 8-1085096

17. Berzigotti A, Gilabert R, Abraldes JG, Nicolau C, Bru C, Bosch J, García-Pagan JC (2008) Noninvasive prediction of clinically significant portal hypertension and esophageal varices in patients with compensated liver cirrhosis. Am J Gastroenterol 103:1159-1167. https://doi.org/10.1111/j.1572-0241.2008.01826x.x

18. Abbasi A, Butt N, Bhutto AR, Munir SM (2010) Correlation of thrombocytopenia with grading of esophageal varices in chronic liver disease patients. J Coll Physicians Surg Pak 20:369-372

19. Zaman A, Hapke R, Flora K, Rosen HR, Benner K (1999) Factors predicting the presence of esophageal or gastric varices in patients with advanced liver disease. Am J Gastroenterol 94:3292-3296. https://doi.org/10.1111/j.1 572-0241.1999.01540.x

20. Colli A, Gana JC, Yap J, Adams-Webber T, Rashkovan N, Ling SC, Casazza G (2017) Platelet count, spleen length, and platelet count-to-spleen length ratio for the diagnosis of oesophageal varices in people with chronic liver disease or portal vein thrombosis. Cochrane Database Syst Rev 4:CD008759

\section{Publisher's Note}

Springer Nature remains neutral with regard to jurisdictional claims in published maps and institutional affiliations.

\section{Submit your manuscript to a SpringerOpen ${ }^{\circ}$ journal and benefit from:}

- Convenient online submission

- Rigorous peer review

- Open access: articles freely available online

- High visibility within the field

- Retaining the copyright to your article

Submit your next manuscript at $>$ springeropen.com 